University of Nebraska - Lincoln

DigitalCommons@University of Nebraska - Lincoln

1990

\title{
THE OCTOBER 17, 1989, LOMA PRIETA, CALIFORNIA, EARTHQUAKE AND ITS AFTERSHOCKS: GEOMETRY OF THE SEQUENCE FROM HIGH-RESOLUTION LOCATIONS
}

Lynn D. Dietz

U.S. Geological Survey

William L. Ellsworth

U.S. Geological Survey

Follow this and additional works at: https://digitalcommons.unl.edu/usgsstaffpub

Part of the Earth Sciences Commons

Dietz, Lynn D. and Ellsworth, William L., "THE OCTOBER 17, 1989, LOMA PRIETA, CALIFORNIA, EARTHQUAKE AND ITS AFTERSHOCKS: GEOMETRY OF THE SEQUENCE FROM HIGH-RESOLUTION LOCATIONS" (1990). USGS Staff -- Published Research. 371.

https://digitalcommons.unl.edu/usgsstaffpub/371

This Article is brought to you for free and open access by the US Geological Survey at DigitalCommons@University of Nebraska - Lincoln. It has been accepted for inclusion in USGS Staff -- Published Research by an authorized administrator of DigitalCommons@University of Nebraska - Lincoln. 


\title{
THE OCTOBER 17, 1989, LOMA PRIETA, CALIFORNIA, EARTHQUAKE AND ITS AFTERSHOCKS: GEOMETRY OF THE SEQUENCE FROM HIGH-RESOLUTION LOCATIONS
}

\author{
Lynn D. Dietz and William L. Ellsworth \\ U.S. Geological Survey, Menlo Park, CA
}

\begin{abstract}
Hypocenters of the Loma Prieta sequence form a dipping zone that rises from the mainshock hypocenter and is parallel to the mainshock nodal plane. Most aftershocks cluster around the perimeter of the zone, surrounding a relatively aseismic center which approximates the region of mainshock rupture. At its southeastern end, the dipping aftershock zone warps into a vertical surface that comesponds to the San Andreas fault. In the central and northwestern parts of the zone at depths above $-10 \mathrm{~km}$, the aftershocks define numerous disjoint fault structures. The large component of reverse-slip observed in this event agrees with a simple model for slip on a dipping plane within a compressional fault bend. We do not believe that the Loma Prieta earthquake occurred on the Sargent fault. However, we are unable to conclude whether it ruptured the principal plate boundary fault or a less frequently active fault.
\end{abstract}

\section{Introduction}

The $M_{S} 7.1$ Loma Prieta earthquake presents an opportunity to investigate the complete aftershock sequence of a major earthquake over a wide magnitude range and to compare it with the preceding two decades of seismic activity. The U.S Geological Survey has operated a dense, high-gain seismic network (CALNET) covering the southern Santa Cruz Mountains since the late 1960 's that permits highresolution hypocentral determinations on a routine basis [Eaton et al., 1970].

In this paper we introduce a refined traveltime model for the Loma Prieta source region and apply it to the study of the temporal and spatial patterns seen in the aftershocks from October 18-31 1989. Companion papers by Olson [1990], and Oppenheimer [1990] present the preceding seismicity and focal mechanism solutions for the Loma Prieta sequence, respectively, as based on this crustal model.

\section{Data and Analysis}

At our office located about $40 \mathrm{~km}$ north of the rupture, the three principal data recording systems (Real Time Processor (RTP), on-line digital event detection and seismogram storage computer (CUSP), and analog FM tape recorders) operated without interruption throughout the sequence despite ground motions of $-1 / 4 \mathrm{~g}$ and loss of commercial electrical power for 7 hours. Roughly half of the stations

This paper is not subject to U.S. copyright. Published in 1990 by the American Geophysical Union.

Paper number 90GL01000

0094-8276/90/90GL-01000\$03.00 within about $50 \mathrm{~km}$ of the epicenter were lost for most of the first 20 hours of the sequence. Fortunately, 22 of the nearest stations, including the majority of those within a focal depth of the sequence, remained in full operation except for one 4-hour period when 8 of the 9 stations covering the southern portion of the aftershock zone were lost. As a consequence, our catalog contains some data gaps during the first day of the sequence. After the first day, the completeness level for the catalog approaches $M$ 1.0.

The P-wave arrival data used to locate these earthquakes are a merged set of hand picks from CUSP and machine picks from the RTP. We located the earthquakes with HYPOINVERSE [Klein, 1989] using the station corrections and P-velocity models described below. Of approximately 3750 aftershocks processed thus far for October 1989, we study 1173 of the best-constrained hypocenters here. The selected hypocenters have root mean-square traveltime residual (ms) $<0.2 \mathrm{~s}$, horizontal standard error $<0.5 \mathrm{~km}$, vertical standard error $<1.0 \mathrm{~km}$, number of stations $\geq 8$, and magnitude $\geq 1.3$. The selected events include $70 \%$ of the total number of events $M \geq 1.5$.

Using P-wave traveltimes from the mainshock and 89 aftershocks distributed evenly throughout the aftershock zone, we calculated station traveltime corrections and 1dimensional velocity models (Figure 1) with a joint hypocenter-velocity inversion program (VELEST). Because of obvious differences in surface geology across the San Andreas, we partitioned the stations into two sets corresponding to the northeast and southwest sides of the San Andreas fault and derived a separate velocity model ( 9 layers over halfspace) for each side of the fault.

The velocity structure for the northeast side (Figure 1) compares favorably with the refraction model of Mooney and Colbur [1985] and reflects the uplifted basement within the Santa Cruz Mountains east of the Sargent fault. The lower velocities in the upper $9 \mathrm{~km}$ of the southwest model reflect the underlying Tertiary age and younger sediments to the southwest of the Sargent fault. Velocities below $18 \mathrm{~km}$ are poorly resolved, principally due to inadequate sampling. As a consequence, a tradeoff exists between focal depth and velocity for the deepest events in the sequence. In particular, the depth of the mainshock could be in error by about $1 \mathrm{~km}$.

As a test, we relocated two shots [Mooney and Colbum, 1985] near the aftershock zone with the derived model. Each relocation is displaced about $1 \mathrm{~km}$ from the actual location (Figure 1). Therefore, the locations of earthquakes determined with our model may have systematic errors of about $1 \mathrm{~km}$. The relative locations, however, are more precise and have an average epicentral error of $\pm 0.3 \mathrm{~km}$ and an average vertical error of $\pm 0.6 \mathrm{~km}$. We believe these relative error estimates are conservative, as they include an estimated traveltime reading and modeling error of $0.1 \mathrm{~s}$ in 


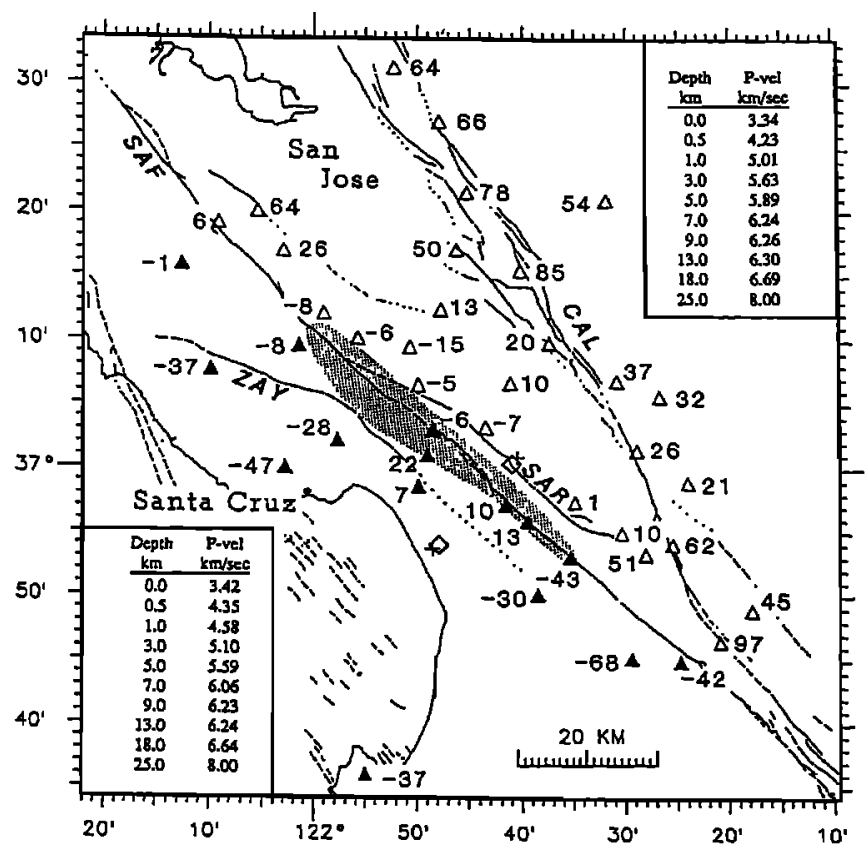

Fig. 1. Locations (triangles) and delays ( $\sec \times 100)$ for the seismic stations used in this study. Solid (open) triangles are stations assigned to velocity-depth profile in the lower left (upper right) inset. Shaded area denotes the aftershock zone. Diamonds show actual locations of shots [SP2, SP3 of Mooney and Colburn, 1985] and +'s show our relocations. Labeled faults are the San Andreas (SAF), Sargent (SAR), Calaveras (CAL), and Zayante (ZAY).

addition to the rms error (mean value $=0.06 \mathrm{~s}$ ) in the error computation.

\section{Geometry of the Sequence}

The Loma Prieta M7.1 mainshock initiated at 0004:15.21 UTC on October 18,1989 , at $37^{\circ} 2.37^{\prime} \mathrm{N} 121^{\circ} 52.81^{\prime} \mathrm{W}$ and at $17.8 \mathrm{~km}$ depth (Figure 2). The 95\% confidence ellipse for this location has semi-major axes with azimuth, plunge and length $(\mathrm{km})$ of $125^{\circ}, 5^{\circ}, 0.48 ; 34^{\circ}, 12^{\circ}, 0.79$; and $234^{\circ}$, $77^{\circ}, 1.39$. By the end of October the aftershocks were occurring over a $60 \mathrm{~km}$ stretch along the San Andreas fault between 2 and $19 \mathrm{~km}$ depth (Figures 2,3). The largest aftershock (M5.2, 37 minutes after mainshock) occurred 23.5 $\mathrm{km}$ northwest of the mainshock at $14.3 \mathrm{~km}$ depth and marks the northern extent of the aftershock zone. The southern end of the aftershock zone overlaps $\sim 3 \mathrm{~km}$ with the seismically active central segment of the San Andreas [OIson, 1990].

To explore the temporal development of the sequence we examine a series of longitudinal cross sections for consecutive times intervals. During the first 24 hours of the sequence (Figure 3a), the majority of events occur along the perimeter of the aftershock zone, a pattern also seen when all of the available locations are considered. The distinct clusters apparent in this early period remain active throughout the duration of the sequence. In contrast to the active perimeter, the center of the zone contains relatively few aftershocks, most of which have focal mechanisms dissimilar to the mainshock [Oppenheimer, 1990]. We believe

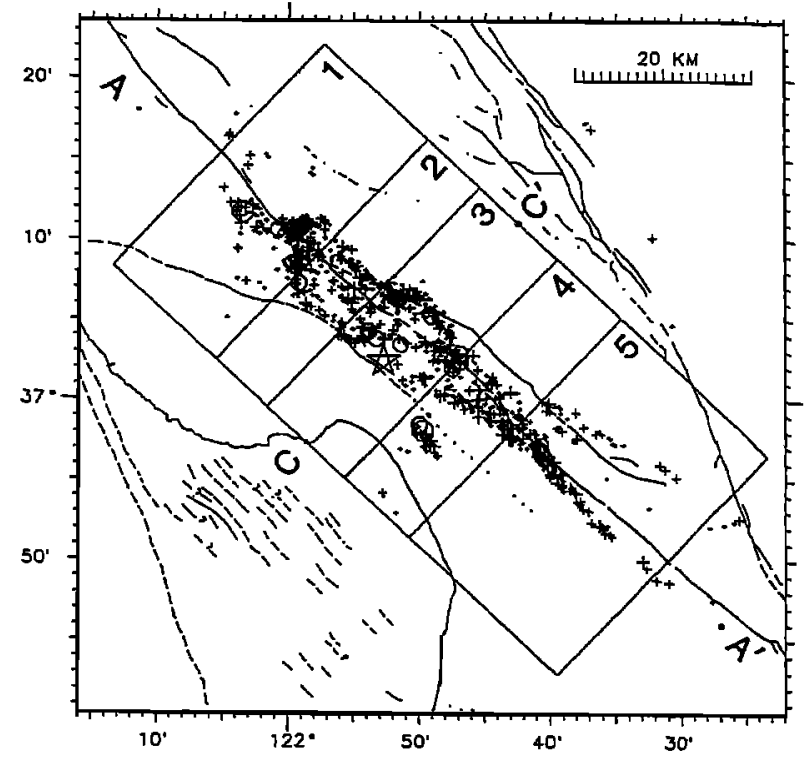

Fig. 2. Epicenters of the mainshock and best-constrained aftershocks from October 18-31, 1989. Star = mainshock, large circle $=M \geq 5.0$; small circle $=M \geq 4.0 ;+=M<4.0$. Symbol size is scaled with magnitude. Labeled points $\mathrm{AA}^{*}$ (CC') denote the cross-sectional endpoints for Figure 3 (Figure 4). Numbered boxes outline regions which are plotted individually in Figure 4.
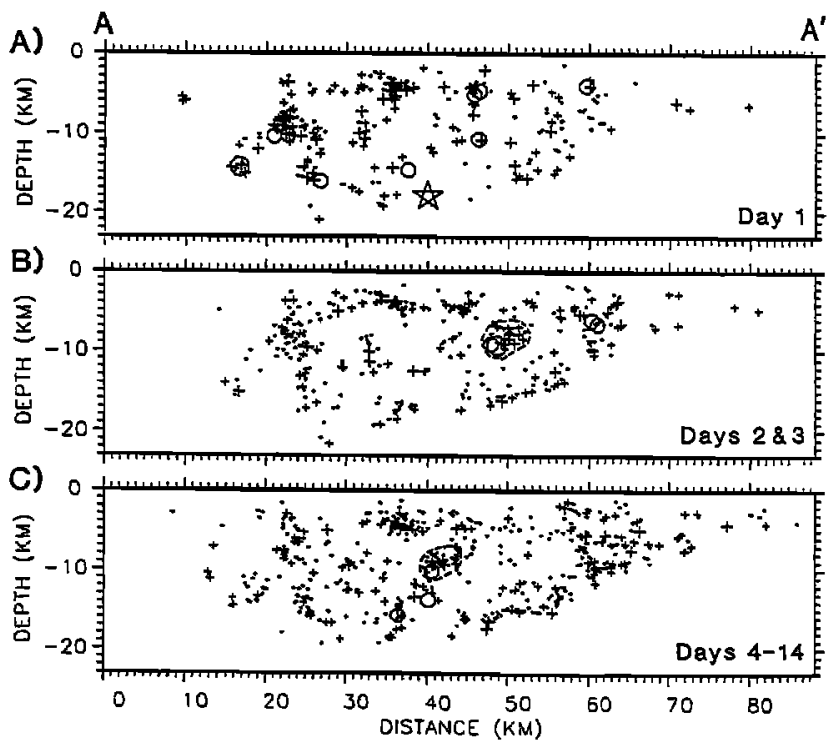

Fig. 3. Longitudinal cross sections for consecutive time intervals after the mainshock: a) $10 / 180000-2400$ b) $10 / 19$ 0000 - 10/20 2400; c) 10/21 0000 - 10/31 2400. Dashed lines surround clusters which locate away from the main distribution of aftershocks. Symbols same as in Figure 2.

that this central aseismic zone generally corresponds to the areal extent of rupture in the mainshock by analogy with recent, well-studied earthquake sequences summarized by Mendoza and Hartzell [1988]. Rupture in the Loma Prieta earthquake thus began at the base and spread unilaterally upward for $15 \mathrm{~km}$ and bilaterally along strike for about 15 $\mathrm{km}$ in either direction. 
Activity during the remainder of October (Figures $3 \mathrm{~b}$ and 3c) reinforces the pattern established on the first day, with most earthquakes continuing to populate the perimeter of the aftershock zone. The two clusters identified on Figure 3 lie away from the main distribution and are discussed below.

A series of transverse cross sections (Figure 4) illustrates the geometric complexity of the sequence. The hypocenters in box 1 describe a single plane with the largest aftershock near its base. In box 2 where the surface traces of the Sargent and San Andreas faults diverge, the aftershock structure is more diffuse, particularly at depths shallower than 12 $\mathrm{km}$. In box 3 the hypocenters below $10 \mathrm{~km}$ fall on a plane dipping approximately $65^{\circ}$ to the southwest with the mainshock at its base. Above $5 \mathrm{~km}$ the aftershock zone appears to broaden. The distinct vertical cluster located northeast of the main distribution between 6 and $10 \mathrm{~km}$ depth (also identified in Figure 3c) is associated with the M4.5 aftershock of October 25 at 0127 UTC. In box 4 the earthquakes again define a simpler surface. The cluster to the southwest of this surface (also noted in Figure 3b) contains to the M5.0 aftershock of October 19 at 1014 UTC. The apparent dip of this cluster disappears when viewed perpendicular to its map-view trend. Finally, in the southernmost box 5 the majority of the aftershocks form a vertical plane beneath the surface trace of the San Andreas fault. Here, the aftershocks partially overlap the normally active northern terminus of the central segment of the San Andreas fault. The transition between the dipping zone to the northwest and vertical zone in this section is achieved by a continuous warping of the sheet of hypocenters beginning in the northwest portion of box 5 .

The generally amorphous appearance of the aftershocks at depths above $10 \mathrm{~km}$ when viewed in cross section resolves into numerous discrete structures when viewed in plan.

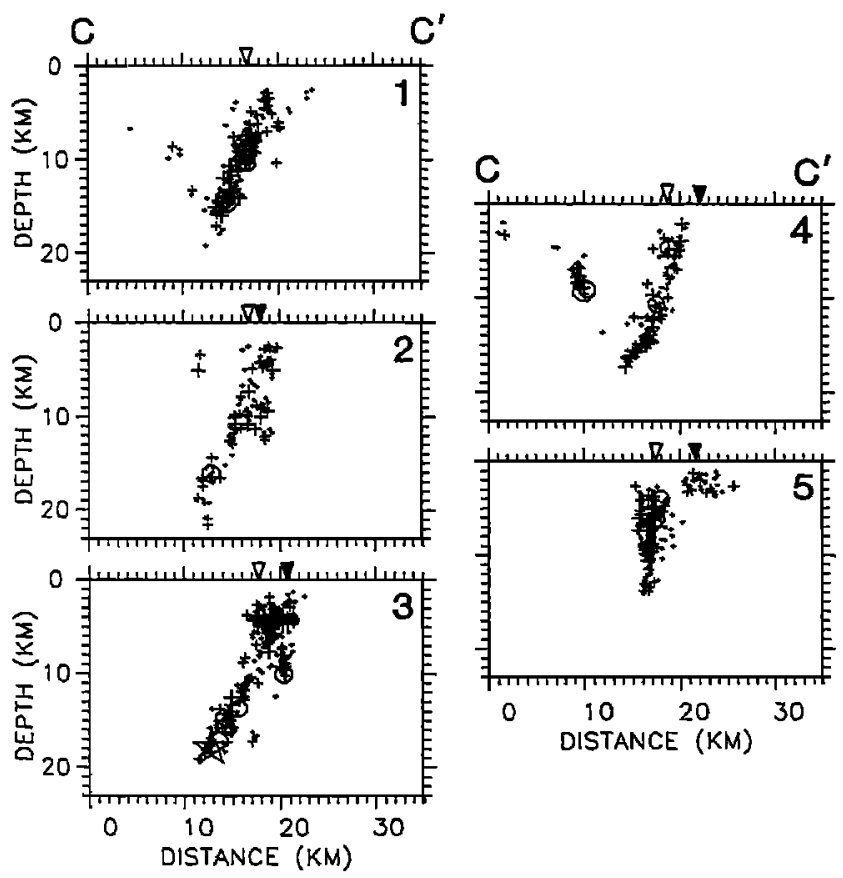

Fig. 4. Series of transverse cross sections along the aftershock zone. Hypocenters and symbols same as in Figure 2. See Figure 2 for the boundaries of each section. Open (solid) inverted triangles denote the position of the surface trace of the San Andreas (Sargent) fault on each section.
Many events locate beneath the surface trace of the San Andreas fault while others group into short linear zones to the northeast of the fault. Events near the San Andreas fault follow the northeastward distortion of the surface trace within the center of the aftershock zone. Some of the discrete zones to the northeast of the San Andreas appear to be associated with the Sargent fault while others have distinctly different strikes or lie well off the trace, suggesting that secondary fault slip was induced by the mainshock on numerous structures.

\section{Discussion}

The general distribution of aftershocks describe a simple, nearly planar structure rising from the mainshock to a depth of about $10 \mathrm{~km}$. The best-fitting plane to this zone (Figure 5) strikes $\mathrm{N} 51^{\circ} \mathrm{W} \pm 2^{\circ}$, dips $65^{\circ} \mathrm{SW} \pm 5^{\circ}$, and coincides with the fault plane solution for the mainshock [Oppenheimer, 1990]. At its south end the plane steepens and merges smoothly with the San Andreas fault seismicity. Above 10 $\mathrm{km}$ the dipping plane could continue upward for several $\mathrm{km}$. It is tempting to extrapolate this plane to the Sargent fault, as might be suggested by Figure 4 . However, above $5 \mathrm{~km}$ seismicity principally occurs on discrete secondary structures. Our analysis of a 3-dimensional model of the hypocenters and the consideration of the focal mechanisms for the shallow activity [Oppenheimer, 1990] fail to support an association with the Sargent fault.

The identification of the deep planar structure as aftershock activity on the main slip surface would be a simple interpretation of the aftershock pattern. However, the focal mechanisms of aftershocks within this structure contradict this "standard" interpretation. Few focal mechanisms in the central part of the dipping zone bear any resemblance to the mainshock [Oppenheimer, 1990], and many of the larger events do not even correspond to strain release within the San Andreas fault system [Michael et al., 1990]. Only within the southernmost part of the aftershock zone do most mechanisms correspond to right-lateral slip on a single fault plane. Within the center of the zone, some of the events in spatial association with the San Andreas release dextral
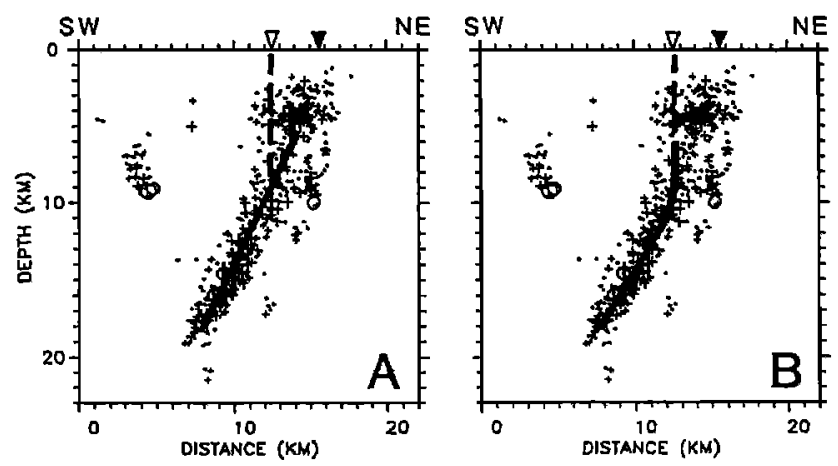

Fig. 5. Two rupture scenarios for the Loma Prieta mainshock. Hypocenters from boxes 2, 3 and 4 in Figure 2 are plotted here. The view is rotated slightly counterclockwise from that shown in Figure 4. The heavy solid line denotes the possible mainshock rupture; the heavy dashed line represents the position of the San Andreas fault. In a) the rupture truncates the San Andreas fault and in b) rupture occurs on the San Andreas which dips below $10 \mathrm{~km}$. 
shear stress. Many others, however, release fault-normal compression on reverse faults. At the north end of the aftershock zone, reverse faulting predominates, releasing the fault-normal compressional component of the stress field.

The surprisingly large amount of reverse slip in the mainshock has led many to question whether or not this event is typical of this portion of the plate boundary. At first appearance, the nearly equal ratio of reverse slip to strike slip in the earthquake seems implausible as representing the average behavior for a part of the San Andreas fault. Within the southern Santa Cruz Mountains, however, the San Andreas fault makes a prominent left (compressional) bend, connecting straighter subparallel segments to the north and south. Over geologic time, excess crust must be removed from the bend as the fault moves, either by lateral flow, subduction or mountain-building.

We propose a simple kinematic model for movement on a dipping plane within a compressional bend of a vertical strike-slip fault. Horizontal motion along this plane is described by $u \cos \theta$ and dip-slip motion by $u \sin \theta / \cos \phi$, where $u$ is the slip velocity outside of the bend, $\theta$ is the change in fault strike, and $\phi$ is the dip of the plane. In the region of the Loma Prieta earthquake, the surface trace of the San Andreas differs in strike by $10^{\circ}$ to $15^{\circ}$ from its adjoining segments. The fault plane defined by the aftershocks dips $65^{\circ} \pm 5^{\circ} \mathrm{SW}$. The above equations predict a ratio of horizontal to reverse slip on this plane between 2.8:1 (for $\phi=60, \theta=10)$ and 1.3:1 $(\phi=70, \theta=15)$. The component of reverse slip observed in the Loma Prieta earthquake falls within this predicted range. Geodetic models of the earthquake yield a ratio of 1.3:1 [Lisowski et al., 1990].

While this simple model reasonably matches the rake of the Loma Prieta mainshock, it leaves unanswered the larger question of how the San Andreas fault reorganizes itself as it traverses the bend. At a slip velocity of 1.5 to $2 \mathrm{~cm} / \mathrm{a}$ it takes the crust to the southwest of the fault about 2 my to travel through the bend. Lower crustal rocks should crop out southwest of the fault if repetitions on the Loma Prieta earthquake fault plane were the only means of accomodating this motion. However, the modest relief $(-1 \mathrm{~km})$ of the Santa Cruz mountains, their thick Tertiary section, and the location of Loma Prieta peak on the downdropped block suggest that more than one pattern of deformation may occur here.

\section{Which Fault Moved?}

In view of the general characterization of the mainshock rupture and the strain release in the aftershock sequence, how does the Loma Prieta mainshock relate to the San Andreas fault? Based on the geometry of the hypocenters, we see three possibilities for this relationship:

1) The rupture plane truncates a vertical San Andreas fault at $-9 \mathrm{~km}$ depth (Figure $5 \mathrm{a}$ ).

2) The San Andreas fault dips below $10 \mathrm{~km}$ and steepens to vertical above $10 \mathrm{~km}$ (Figure $5 \mathrm{~b}$ ).

3) The San Andreas truncates the dipping rupture at $-9 \mathrm{~km}$ depth and remains vertical adjacent to it [Olson, 1990].
At present the combined seismicity and geodetic data [Lisowski et al., 1990] cannot exclude any of these models. The Sargent fault does not appear to be a candidate for the rupture plane of 1). Some afterhsocks are consistent with activity on a vertical San Andreas fault, but they are few in number and do not define a continuous structure. Other events, in the center of the sequence, release fault nomal compression as would be the case for the growth of the southern Santa Cruz Mountains as a fault propagation fold [Suppe, 1983] above the dipping right-reverse fault. If this is the case, then the "old" San Andreas would be deflected to the northeast as the fold grows, possibly being dismembered into smaller segments. Differences in the vertical deformation expected for each scenario may ultimately permit us to distinguish between these models.

Acknowledgements. We thank the U.S.G.S. CUSP personnel for data processing and D. Eberhart-Phillips, D. Oppenheimer, J. Olson and two anonymous reviewers for their comments and suggestions.

\section{References}

Eaton J.P., W.H.K. Lee, and L.C. Pakiser, Use of microearthquakes in the study of the mechanics of earthquake generation along the San Andreas fault in central California, Tectonophysics, 9, 259-282, 1970.

Klein, F.W., User's guide to HYPOINVERSE, a program for VAX computers to solve for earthquake locations and magnitudes, U.S. Geol. Surv., Open-File Rept. 89-314, 58 pp., 1989.

Lisowski M.J., W.H. Prescott, J.C. Savage, and M.J. Johnston, Geodetic estimate of coseismic slip during the 1989 Loma Prieta, California, earthquake, Geophys. Res. Lett., in press.

Mendoza, C., and S.H. Hartzell, Aftershock patterns and main shock faulting, Bull. Seism. Soc. Am., 78, 1438$1449,1988$.

Michael, A.M., W.L. Ellsworth, and D.H. Oppenheimer, Coseismic stress changes induced by the Loma Prieta, California, earthquake, Geophys. Res. Lett., in press.

Mooney, W.D., and R. Colbum, A seismic-refraction profile across the San Andreas, Sargent, and Calaveras faults, West-central California, Bull. Seism. Soc. Am., 75, 175191, 1985.

Olson, J., Seismicity preceding the 1989 Loma Prieta earthquake, Geophys. Res. Lett., in press.

Oppenheimer, D.H., Aftershock slip behavior of the 1989 Loma Prieta, California earthquake, Geophys. Res. Lett., in press.

Suppe, J., Geometry and kinematics of fault-bend folding, Am. J. Sci., 283, 684-721, 1983.

L.D. Dietz and W.L. Ellsworth, U.S.G.S. MS977, 345 Middlefield Rd, Menlo Park, CA 94025.

(Received February 26, 1990;

Accepted April 12, 1990) 